\title{
$\left.\mathbf{C}^{-}\right\rceil \begin{aligned} & \text { CONGRESO } \\ & \text { INTERNACIONAL }\end{aligned}$
SOBRE \\ SOBRE \\ LF_O FOTOGRAFÍA
}

Congreso Internacional sobre Fotografía

UPV, 5 y 6 octubre 2017

Doi: http://dx.doi.org/10.4995/CIFo17.2017.7168

ISBN: 978-84-9048-604-7

\section{Imágenes, libros, diálogos. Experiencias en la enseñanza de la Historia de la Fotografía en un Grado de Historia del Arte}

\author{
Juan Albarrán Diego ${ }^{a}$, Olga Fernández López \\ ${ }^{a}$ Departamento de Historia y Teoría del Arte, Universidad Autónoma de Madrid, juan.albarran@uam.es bepartamento de \\ Historia y Teoría del Arte, Universidad Autónoma de Madrid, olga.fernandez.lopez@uam.es
}

\begin{abstract}
In this paper we aim to reflect on some teaching experiences developed in the course History and Theory of Photography, that is taken by the students in the second year of the Degree in History of Art at the Universidad Autonoma de Madrid. The referred practices have as their main objectives to highlight the materials aspects of photography, to think on its discursive fields, to explore its centrality as a theoretical object and to foster a critical and dialogical attitude in the classroom.

Keywords: exhibition, dialogue, history of art, history of photography, photobook, photography, teaching practice

Resumen

En este texto pretendemos reflexionar acerca de algunas experiencias docentes desarrolladas en la asignatura Historia y Teoría de la Fotografía, enmarcada en el segundo curso del Grado de Historia del Arte de la Universidad Autónoma de Madrid. Las prácticas aqui referidas tienen como objetivo principal incidir en los aspectos materiales de la fotografia, reflexionar sobre sus ámbitos discursivos, explorar su centralidad como objeto teórico y potenciar una actitud crítica y dialógica en el aula.
\end{abstract}

Palabras clave: exposición, diálogo, fotografía, fotolibro, historia del arte, historia de la fotografia, práctica docente 


\section{Introducción: contexto, objetivos y metodología}

El objetivo de este texto es compartir una serie de reflexiones acerca de algunas experiencias docentes desarrolladas en la asignatura Historia y Teoría de la Fotografía, enmarcada en el segundo curso del Grado de Historia del Arte de la Universidad Autónoma de Madrid. Hemos impartido esta asignatura en varias ocasiones durante los últimos cursos académicos sobre un temario común que nos permitía, desde planteamientos y desarrollos diferentes, intercambiar problemas e impresiones. Nuestra práctica docente está condicionada por el contexto académico de la asignatura: una titulación en que la existen otras materias asentadas en la contemporaneidad en las que también se trabajan contenidos relacionados con la fotografía, siempre desde una perspectiva histórico-téorica. Estas asignaturas son Creación, industria y cultura de masas (primer curso), Artes visuales en el mundo contemporáneo (primer curso), Origen y desarrollo de las vanguardias (tercer curso), Arte desde 1945 (tercer curso) y Prácticas artísticas y audiovisuales en la actualidad (cuarto curso).

El Departamento de Historia y Teoría del Arte de la UAM fue pionero en la introducción de la materia de Historia de la Fotografía en el plan de estudios de la Licenciatura en Historia del Arte, primero como optativa, en el plan que siguió al Real Decreto 1449/1990 de 26 de octubre de 1990, y después como obligatoria. La asignatura comenzó a impartirse en el curso 1995-1996, no sin las reticencias de algunos sectores del profesorado del departamento. En la última modificación del Grado en Historia del Arte, que entró en vigor en el curso 2015-2016, la asignatura pasó a denominarse Historia y Teoría de la Fotografía, decisión tomada por la comisión de modificación del grado y cuyo objetivo era orientar la docencia hacia un territorio teórico, además del histórico. Esto mismo sucedió en la asignatura Historia y Teoría del Cine.

El perfil de nuestro alumnado es muy diverso, por lo que es difícil tratar de definirlo. Dos grupos de estudiantes (210 y 220) cursan cada año esta asignatura y la dinámica de trabajo que se desarrolla en cada grupo es diferente. Ahora bien, es posible detectar algunos cuestiones recurrentes derivadas de las dinámicas docentes que predominan en la educación secundaria, de los tópicos a propósito del arte extendidos en la sociedad y, en menor medida, de las aproximaciones a la historia del arte desarrolladas en otras asignaturas del grado. Entre ellas, podríamos señalar la tendencia a entender ésta como una sucesión lineal de estilos, la centralidad de la figura del autor, la concepción del arte como una práctica vinculada a unas habilidades técnicas concretas (virtuosismo) y a unas cualidades intelectuales abstractas (genialidad), los prejuicios sobre la artisticidad de la fotografía y la carencia de una actitud crítica ante la imagen. Partimos, por tanto, de la conciencia de esos problemas, pero también de las potencialidades inherentes a la heterogeneidad de los grupos y de las aptitudes de los/las estudiantes - cuya media de edad ronda los veinte años - en lo referido a su creatividad, habilidades relacionales, capacidad de trabajo, dominio de las nuevas tecnologías y familiaridad con la imagen fotográfica.

Por otra parte, nuestra práctica docente también está vinculada a nuestros intereses como investigadores en el campo de la historia del arte contemporáneo. Nos hemos aproximado a la fotografía como un campo de trabajo en el que se planteaban problemas de primer orden para la Historia y la Teoría del Arte, como los referidos a la materialidad y reproductibilidad de la imagen, la disolución de la autoría, la transformación de los modos de patrimonialización del objeto artístico, la 
negociación de las representaciones de los sujetos o la reescritura de los relatos de la contemporaneidad. Estas cuestiones atraviesan un temario abierto a las interpretaciones, intereses y modos de trabajo de cada uno de los docentes que se han encargado de la asignatura en los últimos cursos, nosotros mismos y nuestro compañero Luis Fernández Colorado. Con ligeras modificaciones, el programa desarrollado es el siguiente:

1. Sobre la(s) invención(es) del medio fotográfico

2. Fotografía y arte: en torno al Pictorialismo

3. La imagen del otro

4. El estilo documental

5. Ámbitos discursivos: archivo, museo y página impresa

6. Fotografia y (anti)arte: vanguardias

7. El paradigma del instante decisivo y su superación

8. Fotografía y arte contemporáneo

9. La fotografía en la era digital

El temario tiene una cierta orientación cronológica — desde los orígenes a la era digital— que, sin embargo, se quiebra constantemente, pues cada tema da pie a lecturas transversales que recorren la historia de la fotografía. Teniendo en cuenta la titulación en la que se encuadra la asignatura, resulta inevitable que una de sus líneas de trabajo se asiente sobre las fricciones fotografía/arte que se han sucedido, con más o menos intensidad, desde el nacimiento del medio.

A continuación nos referiremos a algunas actividades prácticas que hemos diseñado con el objetivo de desarrollar las competencias recogidas en la guía docente de la asignatura y que, nos gustaría pensar, contribuyen a paliar algunos de los problemas señalados más arriba. Este conjunto de actividades es fruto de la distribución de clases del grado: cada semana, en cada asignatura, se imparten dos horas de clases magistrales teóricas y una hora de prácticas en la que el grupo se divide en dos. La existencia de esta hora semanal, en la que es possible trabajar con un grupo reducido (media clase, unos veinte estudiantes) facilita la realización de actividades ligadas al temario en las que la participación de los alumnos constituye un elemento fundamental. Hay que tener en cuenta que hablamos de la formación de futuros historiadores del arte y de la cultura visual — con perfiles e intereses muy dispares, claro está-, y no de estudiantes de Bellas Artes o Comunicación Audiovisual. Para los estudiantes de Historia del Arte, la enseñanza suele basarse en presentaciones de imágenes digitalizadas y proyectadas. Sin renunciar a ese método, en nuestro caso, otorgamos el mismo peso al trabajo teóricopráctico a partir de textos clave, que se leen, ponen en común y discuten, que al desarrollo de ejercicios dialógicos, performativos y creativos, en los que, entre otros aspectos, se incide en la materialidad de la fotografía, sus ámbitos discursivos y su centralidad como objeto teórico.

\section{Imágenes (y palabras)}

Uno de nuestros objetivos es conectar algunos conceptos claves de la teoría fotográfica con imágenes concretas, con el fin de que los alumnos adquieran un vocabulario básico del campo de estudio que puedan emplear en sus trabajos de clase. Entre otros conceptos se analizan: aura, inconsciente óptico, 
pulsión escópica, índice, instante decisivo, studium y punctum o belleza convulsa. Para acercarnos a las fuentes originales, los estudiantes leen los textos claves de André Breton y Roland Barthes en torno a los conceptos de "belleza convulsa" y "punctum". En relación a "punctum", en su casa debían buscar fotografías que pudieran ser analizadas o comentadas mediante este concepto. A la sesión de trabajo práctico en el aula, cada estudiante llevaba un breve texto en el que explicaba por qué la imagen elegida podría leerse desde el ensayo. La práctica se completaba con una puesta en común y discusión de las imágenes propuestas. El ejercicio nos ayudó a detectar las dificultades que los estudiantes encontraban para comprender conceptos abstractos. En otra variante de la práctica, durante la clase, los estudiantes se dividían en pequeños grupos y buscaban en sus ordeandores portátiles o dispositivos móviles imágenes que se correspondiesen con el concepto de "belleza convulsa" y la enviaban por correo. Una vez proyectada en clase, cada grupo explicaba a sus compañeros en qué medida la imagen seleccionada encajaba o no en la definición del concepto.

En otra práctica también orientada hacia la puesta en relación de imágenes y textos, primero se proyectaba la película La jetée (Chris Marker), una obra donde la narración se desarrolla a partir de la sucesión de fotografías. Este procedimiento se comenta con los alumnos en clase. Posteriormente se proyecta una fotografía que funciona como un "mapa mudo" y que se cuelga en el campus virtual (moodle). Se pedía a cada estudiante que redacte en su casa una pequeña narración a partir de la imagen. Todas las narraciones, muy distintas entre sí, deben ser leídas y pueden ser comentadas (en el foro virtual) por el resto de compañeros. El ejercicio permite reflexionar acerca de la narratividad de las fotografías en un momento histórico en el que se trata de superar el paradigma del instante decisivo a partir de los años setenta. Al mismo tiempo, la práctica evidencia las contaminaciones ficcionales provenientes del cine y la TV a la hora de leer imágenes fotográficas.

Una de las hipótesis de partida que sustenta nuestro trabajo con los estudiantes pasa por asumir que los significados de las fotografías dependen de sus contextos de circulación y recepción. En ese sentido, nos parece importante trabajar en torno a los principales espacios de legitimación y signficación de la fotografía como arte: exposiciones, colecciones y libros. En los últimos años, hemos podido visitar con nuestros estudiantes algunas exposiciones, dentro y fuera de Madrid, entre las que podríamos destacar Ellen Kooi. Undertones (Centro de Arte de Alcobendas, noviembre de 2014), Fotos \& Libros. España, 1907-1977 (Museo Reina Sofía, ocubre de 2014), Mujeres fotógrafas en la Colección del IVAM (IVAM, abril de 2014) o Miguel Trillo. Doble exposición (CA2M, septiembre de 2017). También hemos visitado, en esas mismas salidas programadas, los almacenes en los que se conservan las colecciones de varias instituciones (IVAM, Centro de Arte de Alcobendas, CA2M). Gracias a esa experiencia hemos podido discutir in situ propuestas curatoriales - discursos, montajes - , en ocasiones acompañados de responsables de las instituciones - Rocío Robles, Museo Reina Sofía; Ana Peláez y José María Díaz Maroto, Centro de Arte de Alcobendas; María Asunción Lizarazu, CA2M- y conocer de primera mano los problemas de conservación de la fotografía.

\section{Libros}

Hay que tener en cuenta que nuestro alumnado — casi todos ellos, nativos digitales - tiende a olvidar los problemas inherentes a la materialidad de la imagen fotográfica. Las imágenes que consumen de 
manera habitual circulan por la red y se proyectan en las pantallas de sus teléfonos móviles $\mathrm{u}$ ordenadores. Hablamos de una generación que apenas ha leído periódicos o revistas en papel. Para nosotros es importante que los estudiantes comprendan que la fotografía no es sólo un imagen líquida, sino que también es - o ha sido - un objeto, que tiene una materialidad, que puede degradarse por un problema de conservación o que puede tocarse impresa en un libro o una revista ilustrada.

Uno de los ámbitos privilegiados para la difusión de proyectos fotográficos hoy es el fotolibro. El formato nos interesa no sólo por su actualidad, sino porque nos permite manipular un objeto fotográfico: de alguna manera, hojeando un fotolibro estamos tocando fotografías, experimentamos de una forma no exclusivamente visual un conjunto de imágenes que tienen un sentido como tal. Por otra parte, algunos de los proyectos que marcaron un hito en la historia del medio se difundieron en forma de fotolibros. Así, pensamos una actividad práctica que pudiese implicar a un grupo amplio de estudiantes en el análisis, discusión y exposición de fotolibros. Para ello, dividimos al grupo en varios subgrupos, tantos como libros van a ser analizados - entre 6 y 8, en nuestro caso-. Los libros con los que habitualmente trabajamos son los siguientes: Walker Evans, American Photographs (1938), Edward Steichen, The Family of Man (1955), Robert Frank, The Americans (1958), Miguel Delibes y Ramón Masats, Viejas historias de Castilla La Vieja, (1964), Mario Vargas Llosa y Xavier Miserachs, Los Cachorros (1967), Richard Billingham, Ray's a Laugh (1996), Alex Rivera, In Amorica. East to West (2010) y Alvaro Deprit, Suspension (2014) ${ }^{1}$.

Con esta selección, tratamos de cubrir un arco importante de la historia de la fotografía, desde los años cuarenta hasta la actualidad, incorporando a su vez aportaciones provenientes del contexto español. Cada subgrupo de alumnos recibe un libro acompañado de una ficha que contiene una información muy somera sobre el mismo y unas preguntas en torno a las cuales deben trabajar en equipo durante una hora. Estas son las preguntas tipo, comunes a todos los fotolibros:

1. ¿Cuál es el nexo que articula las imágenes como conjunto?

2. ¿Cuentan las imágenes una "historia", construyen una "narración”?, ¿de qué tipo?

3. ¿Qué tipo de imagen predomina en términos formales?, ¿planos generales o primeros planos?, ¿qué formato (vertical u horizontal)?, ¿qué encuadre o punto de vista (frontal, oblicuo, picado, contrapicado)?, ¿qué tipo de composición?, ¿puede localizarse una constante formal o simbólica en el uso de la luz?, ¿ocupan las fotografías toda la página o sólo una parte de la misma...?

4. ¿Qué relación podría establecerse entre estos elementos formales y el contenido o sentido del conjunto? ¿Cómo se relacionaría la "estética" de las imágenes con el concepto (si es que existe) que subyace al proyecto?

\footnotetext{
${ }^{1}$ Se utilizan las siguientes ediciones: Walker Evans, American Photographs, Nueva York, MOMA, 1938 (edición conmemorativa del 75 aniversario Tate / MOMA, 2013); Edward Steichen, The Family of Man, Nueva York, MOMA, 1955 (12 $2^{\mathrm{a}}$ reimpresión de la edición conmemorativa del 30 aniversario, 1985); Robert Frank, The Americans, París, Robert Delpire, 1958 (reedición de Steidl, 2008); Miguel Delibes / Ramón Masats, Viejas historias de Castilla La Vieja, Barcelona, Lumen, colección Palabra e Imagen, 1964 (reedición de La Fábrica, 2010); Mario Vargas Llosa / Xavier Miserachs, Los Cachorros, Barcelona, Lumen, colección Palabra e Imagen, 1967 (reedición de La Fábrica, 2010); Richard Billingham, Ray's a Laugh, Zurich, Scalo, 1996 (reedición de Errata Editions, 2014); Alex Rivera, In Amorica. East to West, 2010 (autoedición); Alvaro Deprit, Suspension, Rotterdam, Viewbook, 2014.
} 
Durante la segunda hora de la práctica, cada subgrupo comparte con el resto de la clase los resultados de su análisis. Para ello, presentan el libro ante una cámara que proyecta su imagen — las páginas seleccionadas para ilustrar un argumento, una observación - sobre una pantalla. Es decir, las conclusiones a las que cada grupo ha llegado a partir de las preguntas planteadas deben apoyarse siempre en el fotolibro trabajado. De algún modo, la clase se convierte en una pequeña historia del fotolibro construida por los propios alumnos desde su trabajo colectivo.

\section{Diálogos}

La retirada relativa del profesor con el objetivo de ceder el protagonismo a los estudiantes en la elaboración de las sesiones prácticas es también la tónica en las clases dedicadas a la discusión de textos. Al inicio del curso académico, proponemos una serie de lecturas obligatorias de autores claves en el campo. Aunque la nómina cambia cada año, cabe reseñar la recurrencia de John Tagg, Martha Rosler, Victor Burgin, Allan Sekula, Christopher Phillips, Jeff Wall, Geoffrey Batchen, Ariella Azoulay, Hasan López, Víctor del Río o Joan Fontcuberta. Las lecturas que facilitamos al inicio de cada curso están disponibles en el moodle de la UAM, pero además los alumnos tienen acceso a través de dropbox a un "reader", un compendio de lecturas, que recopiló el profesor Fernández Colorado y que cuenta con 80 textos divididos en los 9 bloques del temario. Los estudiantes tienen a su disposición en pdf esa amplia bibliografía, aunque las lecturas obligatorias se limiten a 7.

Con estas 7 lecturas se diseña un calendario para trabajar aproximadamente un texto cada dos semanas. Cada grupo se divide previamente en subgrupos de 2-4 estudiantes. A cada subgrupo, a su vez, se le asigna una de las lecturas, de modo que deben presentar el texto y conducir una discusión en torno a la misma con el resto de sus compañeros, que, se supone, han trabajado también la lectura. Esta actividad, habitual en nuestros contextos académicos, mantiene, a nuestro entender, varias posibilidades de aprendizaje. En primer lugar, motiva una lectura detenida de textos básicos en la Historia de la Fotografía, pero también fomenta el trabajo colaborativo, mejora la capacidad de exponer ideas complejas y, sobre todo, fomenta el diálogo entre los estudiantes, que se sienten capaces de producir los contenidos de la asignatura. Las formas de presentar y debatir esos textos son siempre muy diversas. En esas sesiones resulta evidente el interés de lxs estudiantes por traer al presente los problemas que subyacen a las lecturas, tales como Tagg y las sociedades de control, Rosler y las imágenes de los refugiados o Fontcuberta y las redes sociales, lo cual resulta siempre estimulante y consigue vincular contenidos históricos con temas de actualidad.

La voluntad dialógica que impulsa nuestra práctica - al margen de cuáles sean sus desarrollos y resultados, no siempre satisfactorios - no se limita a los agentes implicados en la docencia estudiantes / profesores-, sino que también hemos tratado de extenderla a otros especialistas en la materia. Ese es el principal objetivo del seminario anual Políticas de la (no)imagen, que pusimos en marcha en el curso académico 2013-2014 junto a la investigadora Inés Plasencia y que este año alcanza su cuarta edición. Invitando a artistas, historiadores y teóricos a intervenir en nuestro contexto académico queremos profundizar en algunos problemas que nos interesan como investigadores y docentes. El público de esta actividad está conformado, principalmente, por nuestros estudiantes de 
Historia y Teoría de la Fotografía, aunque también por algunos alumnos de máster y doctorado interesandos en el tema. Los títulos de los tres seminarios desarrollados hasta el momento han sido Una aproximación a las teorías y prácticas fotográficas de la contemporaneidad, Fotografía y violencia política y Desaparición, duelo y representación ${ }^{2}$.

En estos encuentros nuestros estudiantes han tenido la oportunidad de conocer de primera mano las investigaciones de reconocidos especialistas en el campo que han compartido con nosotros aportaciones que ampliaban en varias direcciones los contenidos del temario de la asignatura. En nuestra opinión, sus conferencias constituyen, además, modelos de trabajo. Es decir, un joven estudiante, que tiene que enfrentarse en el marco de ésta y otras materias a la redacción de un pequeño trabajo de investigación y que pronto, en cuarto curso, tendrá que producir un Trabajo de fin de grado, puede encontrar en las presentaciones de los participantes en nuestro seminario formas de trabajo documentación, argumentación, exposición - que emular, y no solo contenidos, datos e ideas más o menos provechosos.

Con el objetivo de obtener un retorno crítico de los estudiantes, les pedimos que nos entreguen una breve memoria del seminario en la que traten de poner en relación las distintas intervenciones que lo integran. Muy pocos son capaces de trazar vínculos entre las conferencias de los especialistas convocados, lo cual no solo visibiliza problemas de comprensión y redacción por su parte, sino también - debemos admitir - nuestra falta de coherencia discursiva en la coordinación de algunos de estos seminarios.

\section{Conclusiones}

Nos gustaría pensar que las experiencias a las que nos hemos referido contribuyen a paliar algunos de los problemas señalados en la introducción. Nuestra práctica docente no sigue una línea de trabajo sistemática. Localizamos problemas, los discutimos y desarrollamos actividades prácticas de una manera un tanto intuitiva, asumiendo el riesgo que conlleva toda experimentación y la responsabilidad inherente al trabajo en un espacio de educación superior muy cambiante. Creemos que las actividades que desarrollamos en la asignatura de Historia y Teoría de la Fotografía nos han ayudado a detectar carencias en las dinámicas educativas y en nuestra propia práctica cotidiana y nos ayudan a seguir pensando en al fotografía como un campo de trabajo idóneo en el que repensar cuestiones que atañen a la unicidad de la obra de arte, al concepto de autoría y a la construcción misma de nuestra disciplina.

\footnotetext{
${ }^{2}$ El primero de estos seminarios (13 y 14 de noviembre de 2014, http://arteuam.com/?p=5737) tuvo un carácter introductorio y llevaba por subtítulo Una aproximación a las teorías y prácticas fotográficas de la contemporaneidad. En él participaron, Rocío Robles, María Rosón, Alicia Fuentes, Mar Alberruche, Lidia Mateo, Beatriz de las Heras, Hasán López, Inés Plasencia y Jürg Schneider, divididos en tres mesas. El II Seminario (10 y 11 de diciembre de 2015, http://arteuam.com/?p=6926) tenía como tema Fotografía y violencia política, y contó con aportaciones de Víctor del Río, Álvaro Minguito, Víctor Mora, Aula de Teatro UAM, Simon Njami y Suset Sánchez. Por último en el III Seminario, el último celebrado hasta la fecha, Desaparición, duelo y representación (1 de diciembre de 2016, http://arteuam.com/?p=7451), participaron Victoria Falcó, Arturo Soto, José S Gutiérrez y Carolina Meloni.
} 
Al mismo tiempo, entendemos que la orientación que tratamos de dar a la materia rompe con la verticalidad y unidireccionalidad que predomina no sólo en las enseñanzas de Historia del Arte, sino en la universidad en general. Nuestro principal objetivo seguirá siendo fomentar entre nuestros estudiantes una actitud de desconfianza — reserva, distanciamiento - con respecto a la imagen que, hoy, se demuestra más necesaria que nunca, lo cual sólo es posible desde la visibilización de los marcos de la dotan de significado. Por supuesto, hay un amplio margen de mejora en lo tocante a las prácticas aquí referidas, no siempre productivas y que, como es lógico, no funcionan del mismo modo en todos los grupos, pero también en cuanto a nuestros métodos de evaluación o a la enseñanza de aspectos técnicos. 